\title{
Proveniência e análise sedimentar da porção basal do Grupo Bambuí em Arcos (MG)
} Provenance and sedimentary analysis of the basal portion of the Bambui Group at Arcos (MG)

\author{
Matheus Kuchenbecker ${ }^{1}$, Marly Babinski², Antônio Carlos Pedrosa-Soares ${ }^{1}$, \\ Ricardo Diniz da Costa ${ }^{1}$, Leonardo Lopes-Silva ${ }^{3}$, Felipe Pimenta ${ }^{3}$ \\ ${ }^{1}$ Centro de Pesquisas Professor Manoel Teixeira da Costa, Instituto de Geociências, Universidade Federal \\ de Minas Gerais - UFMG, Avenida Antônio Carlos 6627, CEP 31270-901, Belo Horizonte, MG, BR \\ (alemaogeo@gmail.com; pedrosa@igc.ufmg.br; biduufmg@gmail.com) \\ ${ }^{2}$ Centro de Pesquisas Geocronológicas, Instituto de Geociências, Universidade de São Paulo - \\ USP, São Paulo, SP, BR (babinski@usp.br) \\ 32hoist do Brasil, São José da Lapa, MG, BR (leogeo83@gmail.com; felipegeologia@gmail.com)
}

Recebido em 23 de fevereiro de 2013; aceito em 21 de agosto de 2013

\begin{abstract}
RESUMO
A origem e evolução da Bacia Bambuí é tema de grandes debates, em muito intensificados pela recente corrida exploratória de empresas públicas e privadas em busca de hidrocarbonetos gasosos. Na porção sudoeste da bacia, são raras as oportunidades de se observar o contato basal das rochas sedimentares com seu embasamento, cujas características são cruciais para o entendimento dos processos de instalação da bacia e do início de seu preenchimento. Por meio de testemunhos de sondagem, teve-se acesso a toda a porção basal do Grupo Bambuí na região de Arcos (MG), incluindo seu embasamento. A seção amostrada exibe como embasamento um granodiorito arqueano (c. 2,8-2,9 Ga), fortemente fraturado à época da sedimentação. A unidade basal do Grupo Bambuí é um tilito de alojamento maciço, polimítico, de espessura decimétrica. Grãos de zircão separados da matriz do tilito foram datados e exibem um pico principal de idades em c. 2,8 Ga, indicando proveniência do próprio embasamento. Sobre o tilito repousam calcários impuros, que passam gradativamente para um pacote pelítico, em tendência de preenchimento retrogradacional. Fragmentos terrígenos no calcário impuro sugerem que o embasamento tenha continuado a atuar como fonte durante a sedimentação dos metros iniciais da seção. As rochas pelíticas que ocorrem para o topo têm assinatura litoquímica compatível com fontes ácidas, e possuem idades-modelo Sm-Nd de 1,7 Ga. O acervo de dados sugere que rochas da Faixa Brasília tenham atuado como fonte para as rochas pelíticas, corroborando a interpretação de um caráter foreland para a bacia.
\end{abstract}

Palavras-chave: Bacia Bambuí; Proveniência sedimentar; Zircões detríticos; Idade modelo; Arcos.

\section{ABSTRACT}

The origin and evolution of Bambuí Basin has been a matter of debate, in much intensified by the recent exploratory efforts carried out by public and private companies looking for natural gas. In the southeastern portion of the basin there are rare opportunities to access the contact between the sedimentary rocks and its basement, whose characteristics are crucial to understanding the processes of basin installation and the early sedimentation. The analysis of drill cores allowed us to describe the lowermost Bambuí Group in Arcos (MG) region, including its basement. The sampled section displays as basement an archean granodiorite (ca. $2.8-2.9 \mathrm{Ga}$ ), fractured at the time of sedimentation. The Bambuí Group basal unit is $\mathrm{dm}$-thick, massive lodgment tillite. Grains of zircon separated from the tillite matrix were dated and show a main age peak at ca. $2.8 \mathrm{Ga}$, indicating provenance from the own basement. On the tillite rests an impure limestone that passes gradually to a muddy unit, in a retrogradational filling trend. Terrigenous fragments in the impure limestone suggests that the basement has continued to be a source of sediments in the bottom of the section. The pelitic rocks that occurs to the top has a litochemical signature compatible with acidic source rocks, and shows Sm-Nd model ages of $1.7 \mathrm{Ga}$. These data suggests that rocks from the Brasília Belt have acted as a source for the pelitic rocks, supporting the interpretation of a foreland set for the basin.

Keywords: Bambuí Basin; Sedimentary provenance; Detrital zircons; Model ages; Arcos. 


\section{INTRODUÇÃO}

A Bacia Bambuí, desenvolvida sobre o Cráton do São Francisco ao final da amalgamação do Gondwana (c. 700 $500 \mathrm{Ma}$ ), tem sido um dos mais intrigantes e controversos temas geológicos do Brasil. Atualmente, as atenções novamente se voltaram para essa bacia devido à corrida exploratória de empresas públicas e privadas em busca de hidrocarbonetos gasosos, cujas emanações naturais são conhecidas de longa data (e.g. Martins et al., 1993; Fugita e Clark Filho, 2001; Reis, 2011).

O município de Arcos (MG) localiza-se junto à borda sudoeste da bacia e apresenta larga ocorrência de calcários da porção inferior do Grupo Bambuí - que ali afloram em espessas camadas - , mas são raras as oportunidades de se acessar o contato basal do grupo. Nesse sentido, o presente trabalho oferece uma excelente oportunidade para se conhecer a sequência basal do Grupo Bambuí e seu embasamento, por meio do estudo de testemunhos de sondagem rotativa (realizada cerca de 4 quilômetros a oeste da cidade de Arcos), cedidos por uma empresa atuante na região. Na seção estudada, foram descritas, além das rochas carbonáticas, diferentes tipos de rochas siliciclásticas, que são o foco do presente trabalho. Por meio de análises petrográficas, litoquímicas (elementos traços, incluindo Terras Raras) e isotópicas (U-Pb em grãos detríticos de zircão, Sm-Nd em rocha-total), buscou-se determinar as fontes dos sedimentos, atentando-se para suas implicações geotectônicas.

\section{CONTEXTO GEOLÓGICO}

A Bacia Bambuí corresponde ao locus deposicional das rochas sedimentares do Grupo Bambuí (Martins-Neto e Alkmim, 2001), principal unidade de cobertura pré-cambriana do Cráton do São Francisco (Figura 1). A unidade ocorre em extensas áreas nos estados de Minas Gerais, Bahia, Mato Grosso, Tocantins e Goiás, e, de forma geral, representa um espesso conjunto de rochas pelíticas e carbonáticas depositadas em ambiente marinho plataformal raso a profundo (Dardenne, 1978, 1981; Martins-Neto, 2009). O arranjo estratigráfico da unidade baseia-se, com poucas modificações, nos trabalhos pioneiros de Costa e Branco (1961) e Dardenne (1978, 1981), exibindo, da base para o topo, as formações Carrancas (diamictito, ritmito, arenito), Sete Lagoas (calcário e dolomito, com intercalações pelíticas), Serra de Santa Helena (pelito com lentes de calcário), Lagoa do Jacaré (calcário, siltito), Serra da Saudade (siltito com intercalações de arenito e calcário) e Três Marias (arenito, arcósio, conglomerado). A Formação Samburá (conglomerado, arenito) também integra o Grupo Bambuí, ocorrendo apenas na porção sudoeste da bacia (Castro e Dardenne, 1961).

Apesar de não ser uma hipótese consensual, o Grupo Bambuí tem sido interpretado como registro de uma bacia foreland, desenvolvida em resposta à edificação da Faixa Brasília, a oeste (e.g. Castro e Dardenne, 2000; Alkmim e Martins-Neto, 2001; Martins-Neto et al., 2001; Martins-Neto, 2009).
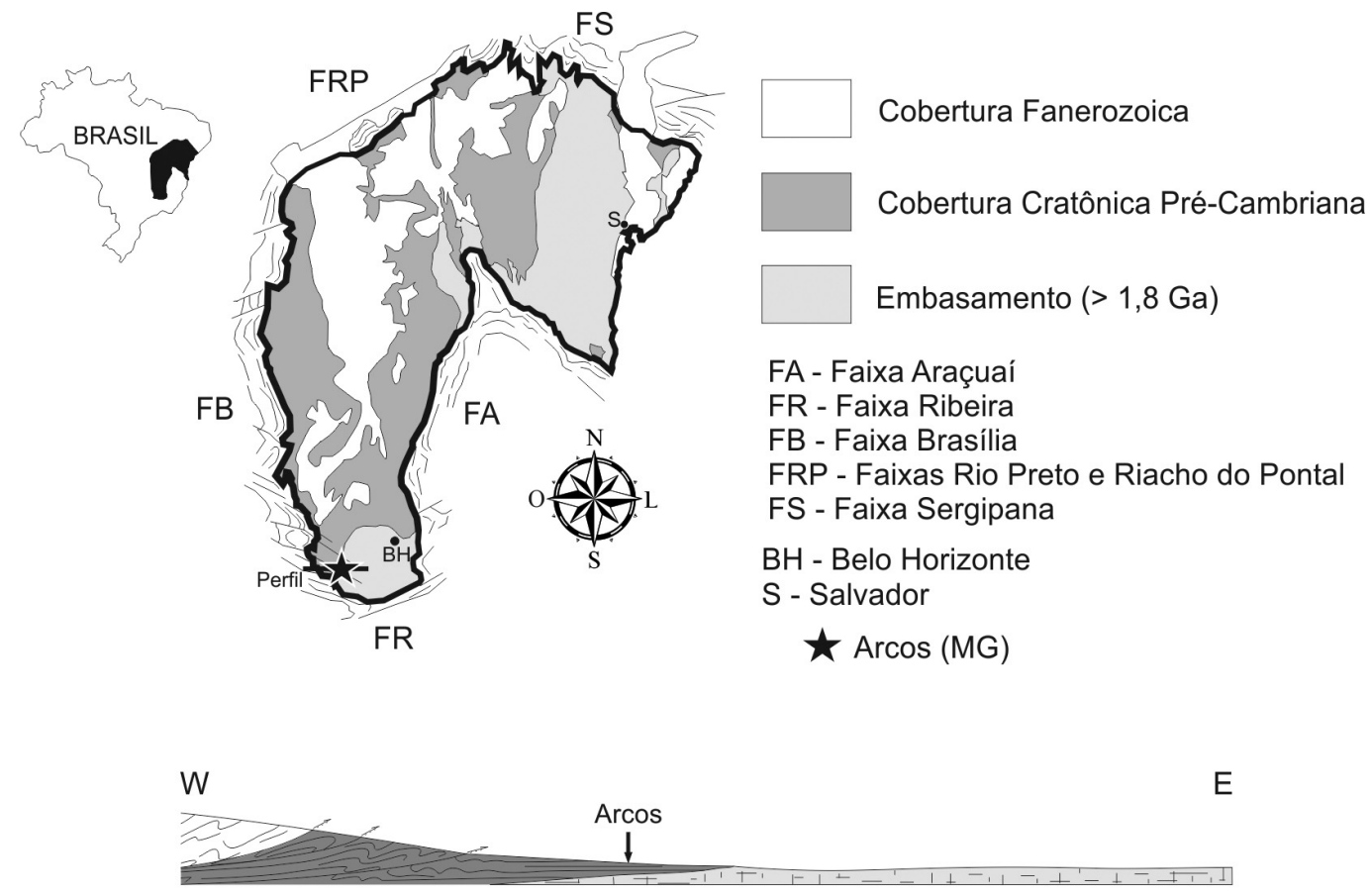

Figura 1. Contexto geotectônico da região de Arcos (MG), na borda oeste do Cráton do São Francisco. O perfil esquemático ilustra a atenuação da deformação para leste e a proximidade das rochas do embasamento. 
A idade de sedimentação do Grupo Bambuí tem sido motivo de intensa investigação. A idade isocrônica $\mathrm{Pb}$ $\mathrm{Pb}$ de $740 \pm 22 \mathrm{Ma}$ foi obtida em carbonatos da Formação Sete Lagoas na porção leste da bacia (Babinski et al., 2007). Contudo, a controvérsia se instalou com o advento das datações U-Pb de grãos detríticos de zircão, tais como as idades em c. 610 Ma relatadas por Rodrigues (2008) para pelitos da porção basal do Grupo Bambuí na região leste da bacia e idades em torno de $540 \mathrm{Ma}$ apresentadas por Paula-Santos et al. (2012) e Pimentel et al. (2012) para a mesma unidade. O conglomerado da Formação Samburá também contém grãos de zircão de c. $620 \mathrm{Ma}$ (Reis et al., 2012). Tal acervo de dados sugere que, ao menos em parte, as rochas do grupo podem ser substancialmente mais jovens.

\section{A PORÇÃO BASAL DO GRUPO BAMBUÍ EM ARCOS}

A base da sucessão sedimentar aflorante em Arcos (MG) apresenta, em seus $50 \mathrm{~m}$ iniciais, sedimentos carbonáticos e siliciclásticos intercalados, registrando uma tendência de preenchimento retrogradacional. A seção, detalhada abaixo, é composta por um diamictito basal recoberto por calcários impuros, que passam gradativamente para um pacote pelítico (Figura 2). Para o topo, em unidades não abordadas neste estudo, o pacote assume caráter francamente carbonático, em tendência de preenchimento progradacional (Kuchenbecker et al., 2011; Nobre-Lopes, 1995). Do ponto de vista litoestratigráfico, as rochas estudadas integram as formações Carrancas e Sete Lagoas (Costa e Branco, 1961).

\section{Embasamento}

Como embasamento tem-se um granodiorito de granulação média, verde escuro a cinza, fracamente foliado. A rocha é considerada como do tipo I e representa um corpo sin a tardi-tectônico intrusivo nos complexos TTG que compõem o embasamento do Cráton do São Francisco na região (e.g. síntese em Kuchenbecker, 2011).

\section{Formação Carrancas - Unidade 1}

$\mathrm{Na}$ base da pilha sedimentar tem-se uma camada de diamictito de $50 \mathrm{~cm}$ de espessura, com contato de topo brusco e concordante com o calcário impuro da Unidade 2.
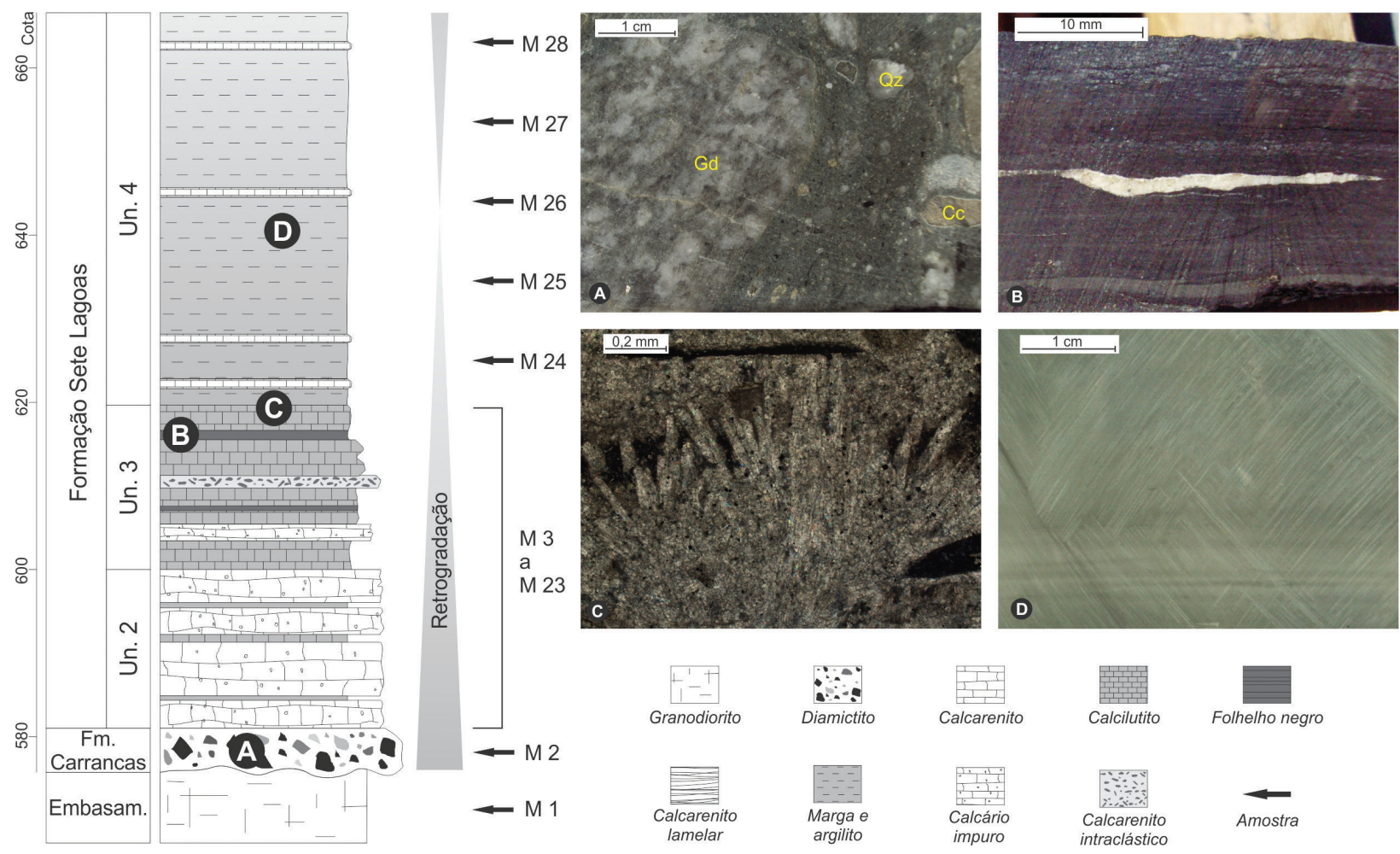

2. Coluna estratigráfica da porção basal do Grupo Bambuí em Arcos (MG). Notar a tendência de preenchimento retrogradacional. (A) Detalhe do diamictito basal, com ênfase para os clastos de quartzo (Qz), granodiorito (Gd) e calcário (Cc); (B) Camada de folhelho negro da Unidade 3, exibindo vênula calcítica paralela ao acamamento; (C) Leques de cristais de calcita, pseudomorfos de aragonita, no topo da Unidade 3. Fotomicrografia, luz analisada; (D) Detalhe de argilito verde da Unidade 4. Notar a presença de lâminas mais claras, carbonáticas, na parte inferior da foto. 
O contato basal é extremamente irregular, indicando um embasamento intensamente fraturado à época de deposição. Uma feição notável observada no contato com o embasamento é uma fratura aberta junto à superfície, cujo espaço foi preenchido por sedimentos de granulometria areia a grânulo, configurando um dique clástico de dimensão centimétrica (Figura 3).

O diamictito é maciço e tem arcabouço composto por clastos de tamanho grânulo a bloco, subarredondados a angulosos. São observados clastos de granitoide, calcário, siltito, cloritito, xisto, formação ferrífera, quartzo e feldspato, que se encontram imersos em matriz esverdeada composta por uma mistura de areia fina e argila (Figura 2A). Os clastos de granitoide guardam grande semelhança com o embasamento e, assim como os clastos de siltito, são em geral maiores e mais arredondados que os demais. Observa-se um aumento na proporção de matriz em direção ao topo da camada. Dado notável é a ocorrência de fragmentos detríticos de cloritito e clorita magnesiana com propriedades óticas anômalas.

Duas amostras de diamictito ( $1 / 4$ de testemunho, diâmetro NQ, $46 \mathrm{~mm}$ ), uma da base e uma do topo da camada, foram escaneadas em alta resolução, para análise de seu padrão textural. Os grãos maiores que $1 \mathrm{~mm}$ foram desenhados e a imagem gerada foi analisada por meio do software ImageTool (Wilcox et al., 2002), para determinação da orientação relativa dos eixos maiores dos objetos desenhados. $\mathrm{Na}$ amostra

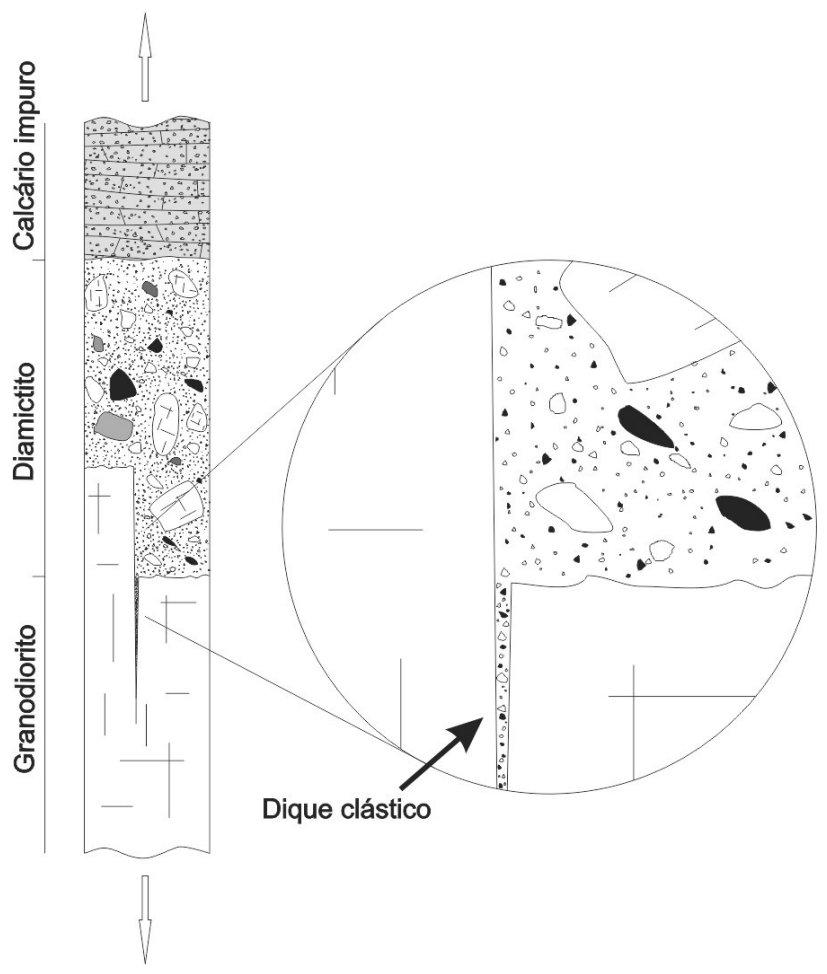

Figura 3. Desenho esquemático exibindo o padrão textural geral da camada de diamictito. Notar o contato irregular com o embasamento e a ocorrência de dique clástico de espessura subcentimétrica. Escala não representativa. da base da camada, verificou-se orientação preferencial dos componentes do arcabouço a $55^{\circ}$ em relação ao plano horizontal (Figura 4A), enquanto na amostra de topo a orientação, apesar de menos evidente, ocorre preferencialmente a $35^{\circ}$ do mesmo referencial. Na amostra de topo, também são visíveis planos descontínuos e irregulares que, por vezes, envolvem grãos (Figura 4B).

\section{Formação Sete Lagoas}

\section{Unidade 2}

Composta por calcário cristalino impuro com camadas de calcilutito, a Unidade 2 tem cerca de $9 \mathrm{~m}$ de espessura e recobre o diamictito da Formação Carrancas por contato brusco. O calcário é cinza claro e apresenta proporções variáveis de fragmentos detríticos que podem chegar a $40 \%$ da rocha. Ocorrem grãos de quartzo, mica, granito, xisto e cloritito, além de intraclastos carbonáticos, em sua maioria angulosos a subarredondados, de dimensões submilimétricas. A exemplo do que ocorre com os clastos no diamictito, os fragmentos de rocha são usualmente maiores que os demais e podem alcançar granulometria areia grossa a grânulo. Apesar da significativa contribuição terrígena, as amostras dessa unidade não renderam grãos detríticos de zircão.

\section{Unidade 3}

Com $8 \mathrm{~m}$ de espessura, a Unidade 3 apresenta uma drástica diminuição no aporte de terrígenos, sendo composta principalmente por calcilutito maciço, com eventuais intercalações de calcarenito impuro e camadas intraclásticas. No topo, passam a ocorrer camadas milimétricas a centimétricas de marga verde clara, registrando o contato gradacional para a unidade sobrejacente. Uma característica peculiar da Unidade 3 é a ocorrência esporádica de lâminas milimétricas a camadas decimétricas de folhelho negro (Figura 2B), que pode apresentar contatos bruscos ou gradacionais com os litotipos carbonáticos. Nessas camadas, é comum a ocorrência de sulfetos disseminados ou concentrados segundo o acamamento.

No topo da unidade, em porção de aspecto bandado e com camadas intraclásticas, ocorrem sucessivas lâminas formadas por cristais de calcita, pseudomorfos de aragonita, em cristais de até $0,2 \mathrm{~mm}$ de comprimento (Figura 2C). Os cristais arranjam-se em forma de leque, partindo radialmente de um ponto no acamamento. Associados a eles ocorrem intraclastos micríticos e agregados de calcita em geometria radial, imersos em matriz esparítica média.

\section{Unidade 4}

Representa um pacote de marga e argilito, com cerca de $25 \mathrm{~m}$ de espessura. A base da unidade é marcada pela 

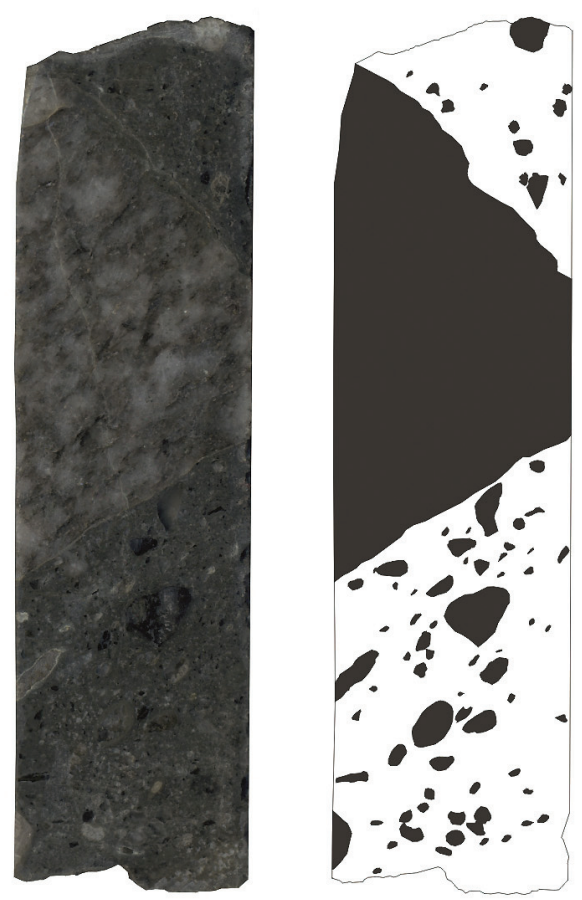

A

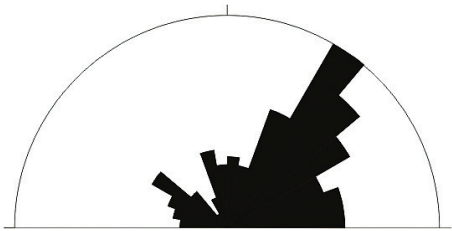

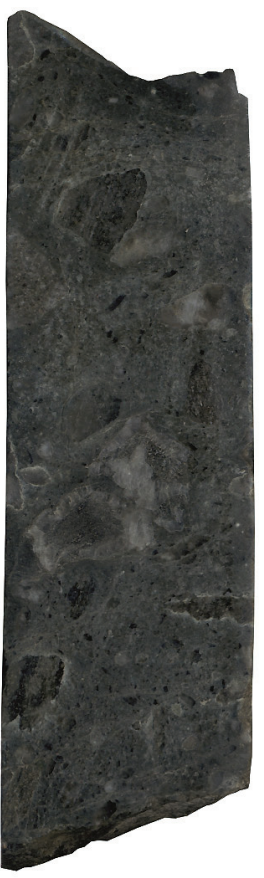

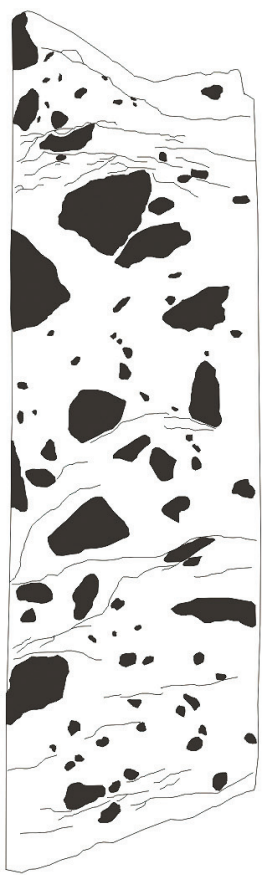

$2 \mathrm{~cm}$

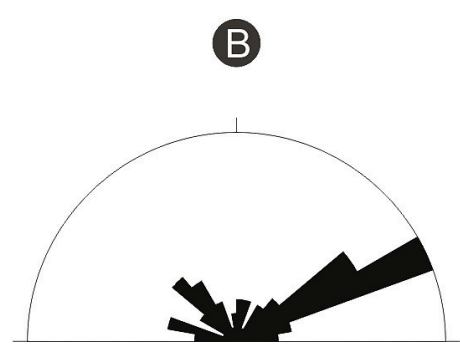

Figura 4. Análise textural das amostras de diamictito. (A) Amostra basal escaneada e desenho dos clastos maiores que 1 mm. $O$ diagrama de roseta indica a orientação preferencial dos eixos maiores dos clastos a $55^{\circ}$ da horizontal. $n=76$; (B) Amostra de topo escaneada e desenho dos clastos maiores que $1 \mathrm{~mm}$. Notar a presença de planos descontínuos, inexistentes na amostra basal. O diagrama de roseta indica a orientação preferencial dos eixos maiores dos clastos a $35^{\circ}$ da horizontal. $n=75$.

ocorrência de marga verde clara, cujo conteúdo carbonático diminui progressivamente, passando a argilito verde mais escuro, maciço, que predomina francamente em sua porção média. Frequentemente, observam-se camadas centimétricas de calcário puro, branco a róseo, nas quais podem ocorrer raras e incipientes construções estromatolíticas - cujo crescimento foi aparentemente inibido pelo grande aporte de argila. Na porção superior, o conteúdo de carbonatos volta a aumentar, retornando à marga.

A Unidade 4 marca a superfície de inundação máxima desse ciclo de preenchimento, registrando, para o topo, o início de um ciclo com tendência progradacional: as unidades sobrejacentes voltam a assumir caráter francamente carbonático, em fácies progressivamente mais rasas (Kuchenbecker et al., 2011).

\section{RESULTADOS ANALÍTICOS}

\section{$\mathrm{U}-\mathrm{Pb}$}

Zircões recuperados do embasamento e do diamictito basal foram datados pelo método U-Pb no Centro de Pesquisas Geocronológicas da Universidade de São Paulo (CPGeo/ USP), utilizando-se a técnica Laser Ablation MultiCollector Inductively Coupled Plasma Mass Spectrometry (LAMC-ICP-MS). Na análise dos cristais, previamente montados em resina epóxi, foi utilizado um equipamento de laser excimer acoplado a um espectrômetro de massa. No processo de ablação, foi utilizado um feixe de laser com $29 \mu \mathrm{m}$ de diâmetro, com frequência de pulso entre 5 e $100 \mathrm{~Hz}$ e energia aplicada variável entre 0 e $20 \mathrm{~mJ}$. 
As partículas removidas do zircão foram transportadas por gás He até a tocha, sendo ali ionizadas. O espectrômetro utilizado foi um NEPTUNE (Thermo Scientific), cujas operações de rotina foram realizadas sob as seguintes condições: energia da rádio frequência $1.200 \mathrm{~W}$, gás de resfriamento a $15 \mathrm{~L} / \mathrm{min}$, gás auxiliar a $0,70 \mathrm{~L} / \mathrm{min}$, fluxo de gás na amostra a $0,75 \mathrm{~L} / \mathrm{min}$ e detectores nas posições ${ }^{202} \mathrm{Hg}=\mathrm{IC} 3,{ }^{204} \mathrm{Hg}+{ }^{204} \mathrm{~Pb}=\mathrm{IC} 4,{ }^{206} \mathrm{~Pb}=\mathrm{L} 4,{ }^{207} \mathrm{~Pb}=$ IC6, ${ }^{208} \mathrm{~Pb}=\mathrm{L} 3,{ }^{232} \mathrm{Th}=\mathrm{H} 2,{ }^{238} \mathrm{U}=\mathrm{H} 4$. As idades foram calculadas em função do padrão internacional GJ (Elholou et al., 2006).

Com o objetivo de se obter uma visão preliminar sobre a idade de cristalização do granodiorito, três cristais de zircão foram datados (U-Pb, LA-ICP-MS, Tabela 1). Os zircões analisados apresentam coloração castanha, são anédricos a euédricos e quase sempre estão fraturados. Em imagem de catodoluminescência observa-se zonamento oscilatório de caráter ígneo nos três cristais, além de pequenas imperfeições que podem representar inclusões. Assim como as fraturas, essas imperfeições foram evitadas no momento da análise (Figura 5).

Os resultados obtidos mostram relativa discrepância, com idades no intervalo de 2,82 a 2,93 Ga. Discordância reversa é observada nas três análises, o que impede a obtenção de uma idade concórdia com esse pequeno número de dados. Ainda assim, as análises sugerem idade arqueana para o granodiorito.

Cinquenta e sete grãos de zircão separados da matriz do diamictito foram datados. Para fins estatísticos, foram consideradas apenas as idades que apresentaram concordância acima de $85 \%$, condição atendida por 34 dos 57 grãos analisados (Tabela 1). Em geral, os grãos de zircão são subédricos e euédricos, e raramente mostram-se arredondados (Figura 6). Observam-se, frequentemente, cristais muito fraturados, enquanto inclusões ocorrem raramente. Em imagem de catodoluminescência (Figura 6), é possível observar zoneamento oscilatório magmático, muito bem definido na maioria dos grãos. Núcleos herdados e bordas de recristalização expressivas não são observados. Do ponto de vista morfológico, a população mais expressiva caracteriza-se por cristais de prismas curtos, com razão comprimento/largura entre 1,5 e 2, enquanto cristais em prismas compridos e cristais sem as faces do prisma bem desenvolvidas ocorrem com bem menos frequência.

As idades ${ }^{207} \mathrm{~Pb} / 206 \mathrm{~Pb}$ obtidas foram plotadas em histograma de frequência (Figura 7A), utilizando-se inicialmente todos os grãos que apresentaram concordância $\geq 85 \%$ (34 grãos). O histograma evidencia a predominância de uma fonte arqueana, com idade em torno de $2,8 \mathrm{Ga}$, além de raras fontes mais antigas (3,12 e 3,47 Ga). Quando plotados apenas os grãos com concordância $\geq 90 \%$ e $\geq 95 \%$ os mesmos picos de frequência são observáveis, apesar do número inferior de medidas.
A existência de uma fonte largamente predominante é reforçada pela disposição dos dados no diagrama concórdia para todos os grãos analisados, inclusive os discordantes (Figura 7B). Os dados exibem uma importante direção de perda de chumbo a partir das idades concordantes obtidas (c. 2,8 Ga) em direção à origem, sugerindo que mesmo os zircões discordantes pertencem à fonte principal.

\section{Sm-Nd}

Análises isotópicas $\mathrm{Sm}-\mathrm{Nd}$ em rocha total foram realizadas em amostras do granodiorito do embasamento, de folhelho negro da Unidade 3 (M14) e argilito da Unidade 4 (M26). As análises foram realizadas no laboratório do CPGeo/USP, onde, para cada amostra, cerca de $50 \mathrm{mg}$ de rocha pulverizada foram dissolvidos via digestão ácida. $\mathrm{Sm}$ e Nd foram purificados por meio da técnica de troca cationnica empregando resinas RE e LN Spec e tiveram suas razões isotópicas medidas em espectrômetro de massa multicoletor Triton. As idades TDM foram calculadas com base no modelo de DePaolo (1981). O branco analítico é de ca. 70 pg Nd e de ca. 20 pg Sm. O valor médio medido para a razão ${ }^{143} \mathrm{Nd} /{ }^{144} \mathrm{Nd}$ do padrão JNdi foi de $0,512098 \pm 0,000013$.

A amostra do granodiorito (M1, Tabela 2) revelou idade modelo TDM de 3,0 Ga, com épsilon $\mathrm{Nd}_{(2,93)}$ de $+1,49$. As duas amostras pelíticas analisadas apresentaram resultados muito semelhantes entre si (Tabela 2). Para o folhelho negro da Unidade 3 foi obtida a idade modelo TDM de $1,7 \mathrm{Ga}$, com $\mathrm{Nd}_{(0)}$ igual a $-16,07$. Para o argilito da Unidade 4 também foi obtida uma idade modelo de 1,7 Ga, com épsilon $\mathrm{Nd}_{(0)}$ igual a $-14,87$, o que pode indicar fonte(s) única(s) para as duas unidades.

\section{Litoquímica}

Amostras das rochas pelíticas das unidades 3 e 4 foram analisadas para elementos traços, incluindo Terras Raras (Tabela 3). As análises foram realizadas no laboratório Acme Labs (Canadá), onde a abundância dos elementos é determinada a partir da fusão de $0,2 \mathrm{~g}$ de amostra com tetraborato de lítio, digestão com ácido nítrico diluído e análise por ICP-OES (elementos maiores e traços diversos) e ICP-MS (Terras Raras). A perda ao fogo é dada pela diferença de peso após fusão a $1.000^{\circ} \mathrm{C}$. Metais preciosos e metais-base são determinados após digestão de $0,5 \mathrm{~g}$ de amostra com água régia e posterior análise em ICP-MS.

Para o estudo de proveniência utilizou-se diversos dos elementos analisados, tendo-se em vista que a composição química das rochas pelíticas, especialmente no que tange a esses elementos, guarda relações com a composição de suas fontes (McLennan, 1989). De acordo com Cullers (2002), as razões $\mathrm{Th} / \mathrm{Co}, \mathrm{La} / \mathrm{Sc}$ e La/Cr 
Tabela 1. Dados isotópicos U-Pb obtidos por Laser Ablasion MultiCollector-Inductively Coupled Plasma-Mass Spectrometry.

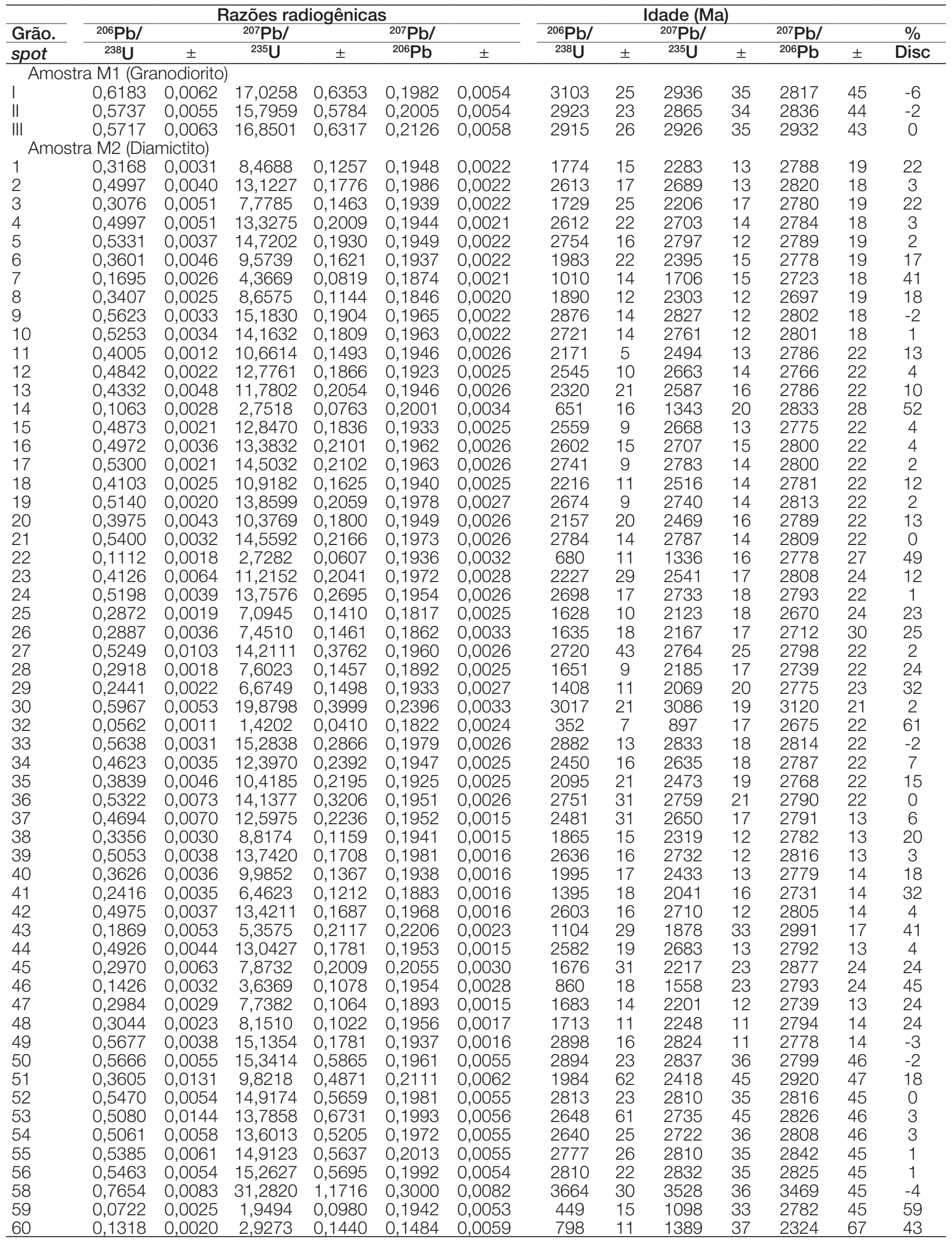


bem como as relações entre esses elementos permitem a diferenciação entre fontes dominadas por rochas básicas ou por rochas ácidas. As amostras de folhelho negro (M16 - Unidade 3) e argilito (M25 - Unidade 4) apresentam razões compatíveis com o campo indicativo de rochas-fonte ácidas. O mesmo acontece no diagrama ternário La-Th-Sc (Figura 8), no qual as amostras situam-se no campo indicativo das rochas ácidas.

\section{DISCUSSÃO E CONCLUSÃO}

A proximidade entre as idades de cristalização e a idade modelo obtidas para o granodiorito do embasamento e o valor positivo de épsilon $\mathrm{Nd}$, aliados às características petrográficas e geoquímicas dessa rocha (Kuchenbecker, 2011) sugerem baixo grau de diferenciação magmática e protólito com contribuição juvenil. Do ponto de vista de correlação regional, a rocha pode representar um corpo intrusivo correlato à unidade granítica do Complexo Campo Belo (Fernandes e Carneiro, 2000).

As rochas carbonáticas das unidades 2 e 3 foram interpretadas, com base em suas características sedimentares e assinatura quimioestratigráfica, como depósitos pós-glaciais, associados a uma das grandes glaciações do Neoproterozoico (Kuchenbecker 2011, Kuchenbecker et al., no prelo).

No cenário de um ambiente glacial, as características do diamictito basal podem fornecer dados importantes sobre os processos atuantes à época. A grande irregularidade do embasamento e a presença de diques clásticos podem ser entendidas como resultado de erosão subglacial, com a fragmentação de blocos favorecida por congelamento e descongelamento de água em fraturas preexistentes na rocha (e.g. Carol, 1947, in Boulton, 1974) e pela variação da pressão da água contida nas fraturas (Bennet e Glasser, 2009). Assim, uma intensa desagregação das porções mais fraturadas do embasamento poderia dar origem a obstáculos e depressões, favorecendo o alojamento de uma eventual carga sedimentar de fundo de geleira. Além disso, esses processos seriam responsáveis pela disponibilização de grande quantidade de clastos do embasamento, encontrados no diamictito.

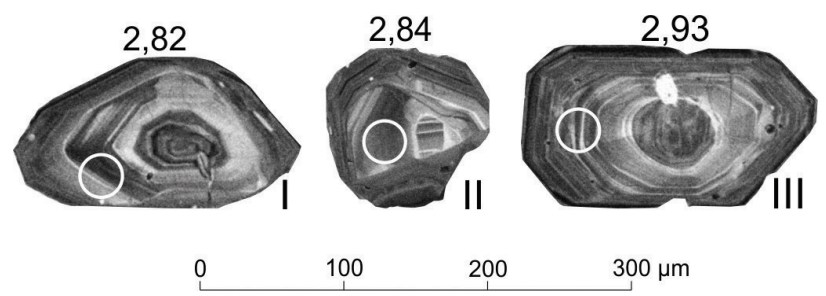

Figura 5. Imagem de catodoluminescência dos zircões do granodiorito analisados. Em todos os casos, o spot possui $29 \mu \mathrm{m}$ de diâmetro. Os números acima de cada grão representam a idade ${ }^{207} \mathrm{~Pb} /{ }^{206} \mathrm{~Pb}$. Os algarismos romanos correspondem ao número do grão, na Tabela 1.
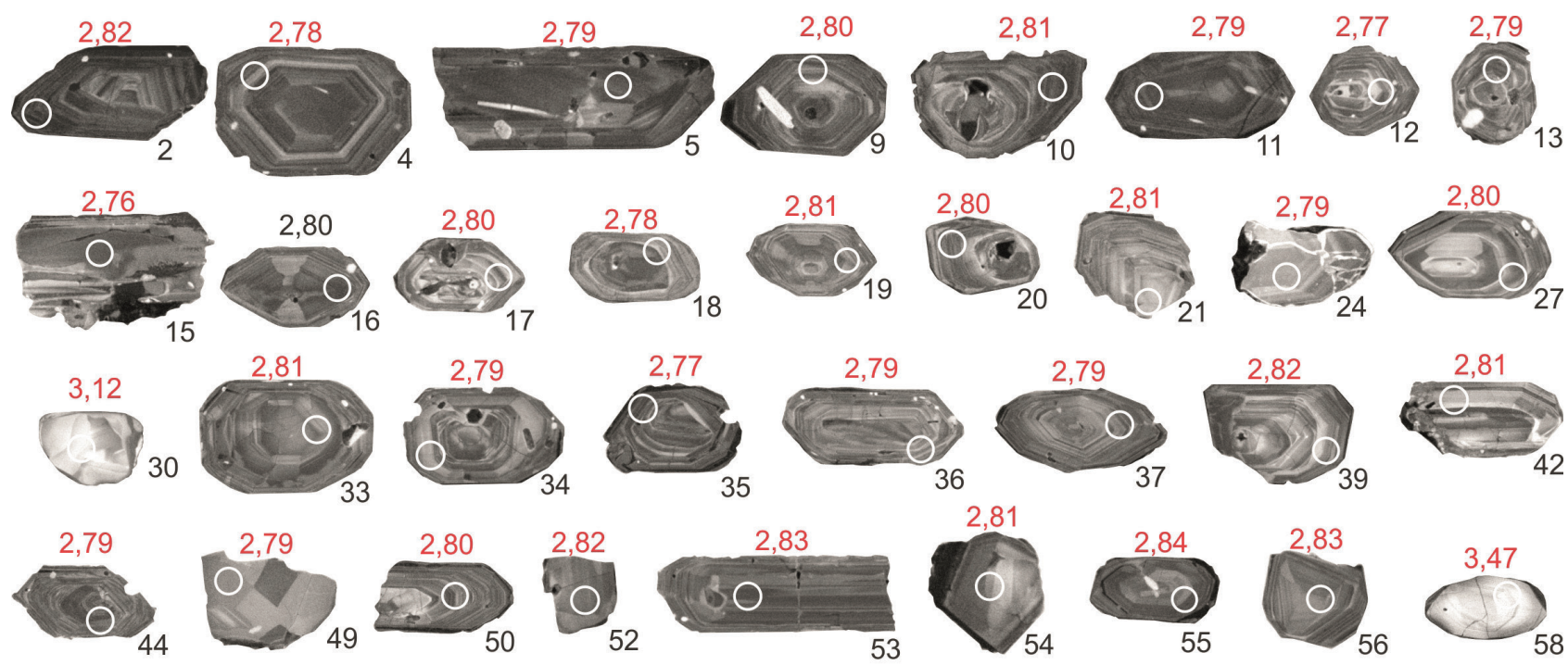

$0 \quad 100 \quad 200 \quad 300 \mu \mathrm{m}$

Figura 6. Imagem de catodoluminescência dos 34 grãos de zircão analisados que apresentaram concordância acima de $85 \%$. O número em preto corresponde ao número do grão na Tabela 1 . Em vermelho, foram plotadas as idades $\left({ }^{207} \mathrm{~Pb} /{ }^{206} \mathrm{~Pb}\right)$. Os círculos brancos correspondem aos spots analisados e têm, em todos os casos, um diâmetro de $29 \mu \mathrm{m}$. 

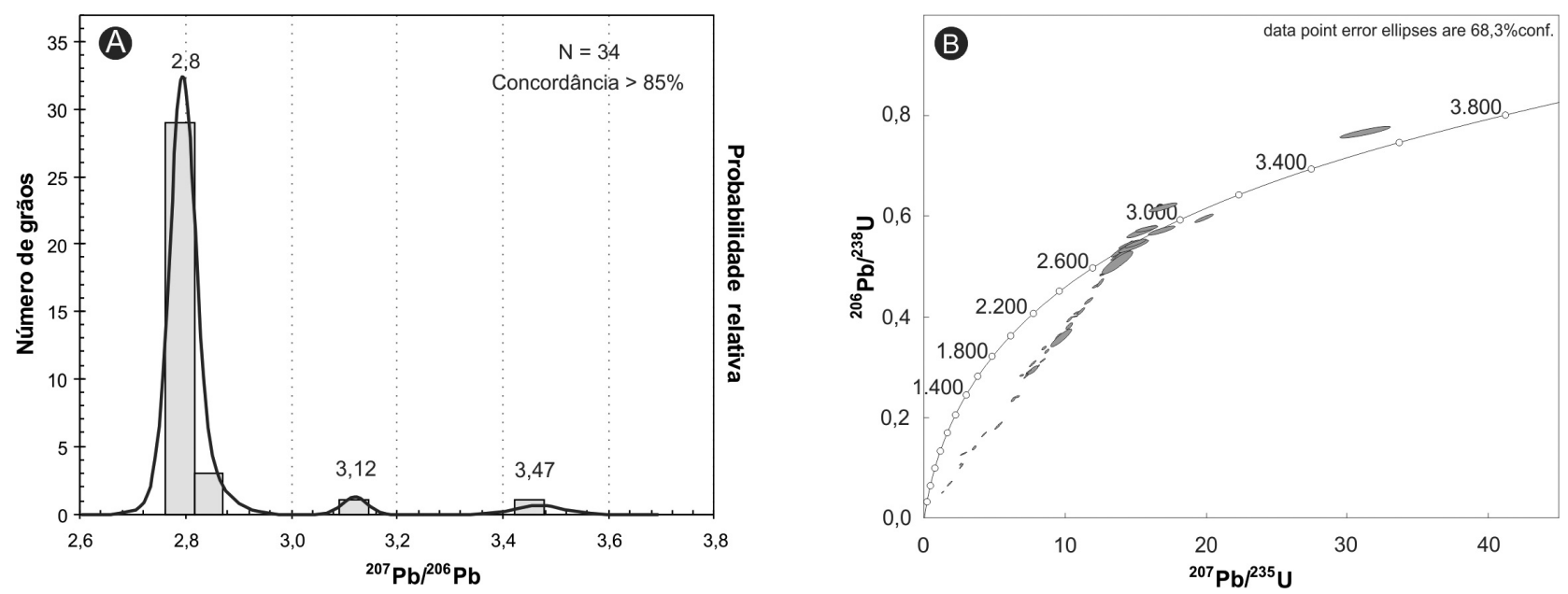

Figura 7. (A) Histograma exibindo a distribuição da probabilidade relativa das idades dos zircões da matriz do diamictito, construído apenas com os grãos que apresentaram mais de $85 \%$ de concordância. (B) Diagrama concórdia exibindo os dados de todos os 57 grãos de zircão analisados. Notar perda de chumbo em direção à origem, a partir da concentração de grãos mais concordantes.

Tabela 2. Dados isotópicos Sm-Nd.

\begin{tabular}{lccccccccc}
\hline Amostra & $\mathrm{Sm}(\mathrm{ppm})$ & $\mathrm{Nd}(\mathrm{ppm})$ & ${ }^{147} \mathrm{Sm} /{ }^{144} \mathrm{Nd}$ & Erro & ${ }^{143} \mathrm{Nd} /{ }^{144} \mathrm{Nd}$ & Erro $(2 \sigma)$ & $\mathrm{T}_{\mathrm{DM}}(\mathrm{Ga})$ & $\boldsymbol{\varepsilon}_{\mathrm{Nd}(0)}$ \\
\hline M1 & 4,903 & 25,427 & 0,1166 & 0,0007 & 0,511164 & 0,000009 & 3,0 & $-28,76$ \\
M14 & 3,850 & 22,969 & 0,1014 & 0,0006 & 0,511814 & 0,000009 & 1,7 & $-16,07$ \\
M26 & 3,936 & 21,381 & 0,1113 & 0,0007 & 0,511876 & 0,000011 & 1,7 & $-14,87$ \\
\hline
\end{tabular}

A orientação preferencial dos clastos observada tanto no topo quanto na base do diamictito, a tendência de mudança dessa orientação para a horizontal em direção ao topo, e os planos descontínuos observados são, também, coerentes com uma gênese glacial. Se considerada uma geleira com carga de fundo, tais feições poderiam resultar de cisalhamento do pacote rudítico ainda inconsolidado pelo fluxo de gelo sobrejacente.

Dentre os diversos tipos de depósitos glaciais existentes, os tilitos de alojamento (lodgement tills) são os que apresentam características mais semelhantes às observadas. São sedimentos acumulados na base de geleiras, que tem, dentre suas feições típicas (Einsele, 1992; Bennet e Glasser, 2009; Tucker, 2003), as seguintes feições: caráter maciço, pequena espessura, possível orientação de clastos pelo fluxo de gelo e possíveis juntas e planos de cisalhamento sin-sedimentares. Além disso, o alojamento e a preservação desses depósitos são sempre favorecidos por irregularidades no leito rochoso. Sendo assim, considera-se que do ponto de vista genético, o diamictito da Formação Carrancas, aqui estudado, é um tilito de alojamento, correspondente a uma fácies glácio-terrestre, associada a uma das glaciações neoproterozoicas.
À época da sedimentação, o granodiorito que constitui o embasamento local estaria previamente fraturado e teria se submetido a processos erosivos subglaciais, intensificados pelas variações de pressão e temperatura da água. Esse processo daria origem a obstáculos e cavidades irregulares no leito rochoso, que propiciariam o alojamento de ao menos parte da carga sedimentar de fundo transportada pelas geleiras. O movimento da geleira sobre a carga alojada e a interação dessa força com a resistência promovida pelas irregularidades causariam a orientação dos clastos, gerando também os planos de cisalhamento paralelos ao plano de deposição.

O padrão de idades do diamictito da Formação Carrancas mostra uma fonte largamente preferencial com idade próxima a 2,8 Ga. Tendo em vista o acervo de clastos descritos e as datações realizadas, considera-se que essa fonte predominante seja o próprio granodiorito do embasamento. Considerando um contexto glácio-terrestre para a sedimentação do diamictito, processos de abrasão subglacial seriam responsáveis pela disponibilização de grande parte da carga sedimentar, explicando assim a larga predominância da fonte local. A grande ocorrência de zircões euédricos a subédricos corrobora essa interpretação, pois indica que o sedimento foi muito pouco transportado. 
Tabela 3. Dados litoquímicos - elementos traços.

\begin{tabular}{|c|c|c|}
\hline Elemento & M16 (Folhelho negro) & M25 (Argilito) \\
\hline $\mathrm{Au}$ & $<0,5$ & $<0,5$ \\
\hline $\mathrm{Ba}$ & 355,00 & 451,00 \\
\hline $\mathrm{Be}$ & 1,00 & 3,00 \\
\hline Co & 29,70 & 23,30 \\
\hline Cs & 6,70 & 10,00 \\
\hline $\mathrm{Ga}$ & 9,20 & 15,30 \\
\hline $\mathrm{Hf}$ & 1,70 & 2,80 \\
\hline $\mathrm{Nb}$ & 6,10 & 10,50 \\
\hline $\mathrm{Ni}$ & 54,00 & 46,00 \\
\hline $\mathrm{Rb}$ & 95,30 & 139,20 \\
\hline Sc & 9,00 & 11,00 \\
\hline Sn & 1,00 & 2,00 \\
\hline $\mathrm{Sr}$ & 261,20 & 124,90 \\
\hline $\mathrm{Ta}$ & 0,50 & 0,80 \\
\hline Th & 31,90 & 11,40 \\
\hline$U$ & 13,20 & 4,10 \\
\hline V & 83,00 & 66,00 \\
\hline W & 107,60 & 85,10 \\
\hline $\mathrm{Zr}$ & 66,60 & 107,10 \\
\hline $\mathrm{Ag}$ & $<0,1$ & $<0,1$ \\
\hline As & 15,60 & $<0,5$ \\
\hline $\mathrm{Bi}$ & 0,20 & $<0,1$ \\
\hline $\mathrm{Cd}$ & 0,50 & $<0,1$ \\
\hline $\mathrm{Cu}$ & 20,80 & 0,80 \\
\hline $\mathrm{Hg}$ & 0,10 & $<0,01$ \\
\hline Mo & 2,30 & 0,10 \\
\hline $\mathrm{Ni}$ & 50,70 & 26,90 \\
\hline $\mathrm{Pb}$ & 11,60 & 1,20 \\
\hline $\mathrm{Sb}$ & 0,50 & $<0,1$ \\
\hline $\mathrm{Se}$ & 1,30 & $<0,5$ \\
\hline $\mathrm{TI}$ & 0,20 & $<0,1$ \\
\hline $\mathrm{Zn}$ & 117,00 & 56,00 \\
\hline $\mathrm{La}$ & 3,60 & 23,10 \\
\hline $\mathrm{Ce}$ & 8,50 & 50,10 \\
\hline $\operatorname{Pr}$ & 1,01 & 5,57 \\
\hline $\mathrm{Nd}$ & 4,40 & 21,90 \\
\hline $\mathrm{Sm}$ & 0,97 & 3,86 \\
\hline $\mathrm{Eu}$ & 0,28 & 0,73 \\
\hline $\mathrm{Gd}$ & 1,19 & 3,43 \\
\hline $\mathrm{Tb}$ & 0,21 & 0,57 \\
\hline Dy & 1,17 & 3,31 \\
\hline$Y$ & 8,30 & 20,00 \\
\hline $\mathrm{Ho}$ & 0,27 & 0,68 \\
\hline $\mathrm{Er}$ & 0,80 & 2,13 \\
\hline $\mathrm{Tm}$ & 0,13 & 0,32 \\
\hline $\mathrm{Yb}$ & 1,00 & 2,15 \\
\hline $\mathrm{Lu}$ & 0,16 & 0,32 \\
\hline
\end{tabular}

Os zircões mesoarqueanos $(3,12 \mathrm{Ga})$ e paleoarqueanos $(3,47 \mathrm{Ga})$ encontrados viriam de fontes mais distantes, o que é indicado pelo arredondamento desses grãos. Como fonte mesoarqueana, sugere-se os complexos TTG (e.g. Campo Belo, Divinópolis) que afloram em grandes áreas em toda a parte meridional do Cráton do São Francisco. Fontes paleoarqueanas são raras nesse cráton e ocorrem apenas como pequenos núcleos, em algumas localidades bem a norte da área estudada (Delgado et al., 2002). A existência de núcleos dessa idade nessa porção do cráton, atuando como fonte, não é descartada, principalmente se consideradas as grandes áreas, hoje cobertas por sedimentos neoproterozoicos que, pelas anomalias gravimétricas, deviam constituir altos do embasamento à época de deposição das unidades estudadas (e.g. Alto de Sete Lagoas, Alkmim, 2004).

Semelhantemente ao diamictito aqui estudado, o rudito da Formação Carrancas que repousa sobre o gnaisse do Complexo Belo Horizonte, na área-tipo dessa unidade (Costa e Branco, 1961), também contém grãos detríticos de zircão com pico principal de idades em c. 2,8 Ga e são interpretados como provenientes do embasamento local (Rodrigues, 2008).

A análise petrográfica das Unidades 1 e 2 sugere a existência de uma área fonte comum a ambas, devido à semelhança entre os fragmentos detríticos encontrados nos carbonatos da Unidade 2 e alguns clastos do diamictito. Como exemplo, citam-se os fragmentos de clorita magnesiana de cor de interferência pouco comum, encontrados nas duas unidades. Assim, tendo em vista que a fonte principal do diamictito é o próprio granodiorito sotoposto a ele, sugerese que esse mesmo embasamento tenha continuado a atuar como fonte durante a deposição da Unidade 2.

$\mathrm{Na}$ Unidade 3 não mais ocorrem fragmentos detríticos em tamanho areia a silte. No entanto, por meio das descrições petrográficas e geoquímicas, constatou-se uma expressiva contribuição de componentes terrígenos em forma de argila. Esse fato sugere uma significativa mudança de fonte, que pode refletir o afogamento de todas as porções do embasamento próximo, o qual não mais atuaria como fonte de sedimentos. No entanto, regiões mais distantes do embasamento poderiam continuar a fornecer sedimentos, agora em tamanho argila.

Em relação à proveniência sedimentar, alterações significativas foram detectadas para as unidades 3 e 4 , tendo-se em vista as idades modelo $\mathrm{Sm}-\mathrm{Nd}$ de 1,7 Ga, que indicam que fontes mais jovens passaram a fornecer sedimentos para a bacia. Em teoria, as idades modelo para rochas sedimentares representam uma média das idades modelo das fontes. Assim, dois cenários podem ser propostos para explicar os dados: (A) Existência de uma única fonte com idade em torno de 1,7 Ga; (B) Mistura entre fontes mais antigas, arqueanas a orosirianas, com fontes mesoproterozoicas e/ou neoproterozoicas. 

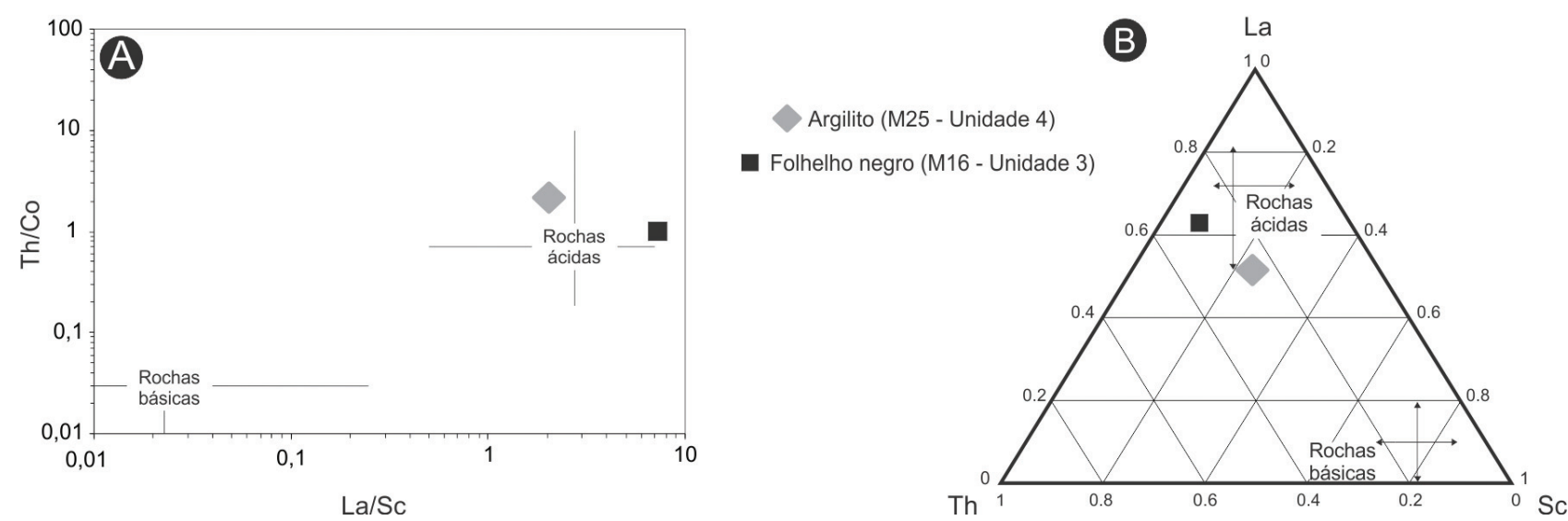

Figura 8. Diagramas indicativos de proveniência para rochas pelíticas, segundo Cullers (2002). (A) Th/Co x La/Sc; (B) Ternário La x Th $\times$ Sc; notar que, em ambos os casos, as rochas analisadas plotam no campo indicativo de proveniência em rochas ácidas.

Considerando que as rochas-fonte destes sedimentos teriam composição ácida (Figura 8), pode-se sugerir algumas possibilidades. Se considerada para a bacia um contexto foreland, teríamos uma região soerguida a oeste para fornecer sedimentos para a bacia (Martins et al., 2001; MartinsNeto e Alkmim, 2001; Martins-Neto, 2009). Na Faixa Brasília são descritas rochas com idade modelo em torno de 1,7 Ga, a exemplo do Grupo Canastra na região de Tapira (Silva, 2006), que poderiam funcionar como fonte única. No entanto, dada a escassez dessas rochas e a distância das mesmas, esta hipótese não parece plausível. Por outro lado, se considerada a grande disponibilidade de rochas ácidas com idades modelo antigas, tanto no Cráton do São Francisco (Complexos TTG) quanto na Faixa Brasília, e a existência de rochas com idades modelo jovens na Faixa Brasília (e.g., Seer et al., 2010; Klein, 2008; Dias et al., 2011; Pimentel et al., 2000) a segunda hipótese parece muito mais viável. Desta forma, as evidências de fonte para os sedimentos pelíticos estudados fornecem outra importante contribuição para a interpretação de um caráter foreland para o Grupo Bambuí.

\section{REFERÊNCIAS}

Alkmim, F. F. (2004). O que faz de um cráton um cráton? O Cráton do São Francisco e as revelações almeidianas ao delimitá-lo. In: Mantesso-Neto, V., Bartorelli, A., Carneiro, C. D. R., Brito-Neves, B. B. de (Orgs.), Geologia do Continente Sul Americano: Evolução da obra de Fernando Flávio Marques de Almeida (17-35). São Paulo: Beca.

Alkmim,F.F., Martins-Neto, M.A.(2001).Abacia intracratônica do São Francisco: Arcabouço Estrutural e cenários evolutivos. In: Pinto, C.P.; Martins-Neto, M.A. Bacia do São Francisco geologia e recursos naturais (9-30). Belo Horizonte: SBG.
Babinski, M., Vieira, L. C., Trindade, R. I. F. (2007). Direct dating of the Sete Lagoas cap carbonate (Bambuí Group, Brazil) and implications for the Neoproterozoic glacial events. Terra Nova, 19(6), 401-406.

Bennett, M. R., Glasser, N. F. (2009). Glacial geology: ice sheets and landforms (2a ed.). Chichester: John Wiley e Sons Ltd.

Boulton, G. S. (1974). Processes and patterns of glacial erosion. In: D. R. Coates (Ed.), Glacial Geomorphology (v. 5, 41-87). Bighamton: The Bighamton Symposia in Geomorphology, international series.

Carol, H. (1947). The formation of rock moutonees. Journal of Glaciology, 1, 58-59.

Castro, P. T. A., Dardenne, M. A. (2000). The sedimentology, stratigraphy and tectonic context of the São Francisco Supergroup at the southern boundary of the São Francisco craton, Brazil. Revista Brasileira de Geociências, 30(3), 345-437.

Costa, M. T., Branco, J. J. R. (1961). Roteiro para a excursão Belo Horizonte - Brasília. XIV Congresso Brasileiro de Geologia, publicação n ${ }^{\circ}$ 15, 9-25. Belo Horizonte: SBG.

Cullers, R. L. (2002). Implications of elemental concentrations for provenance, redox conditions, and metamorphic studies of shales and limestones near Pueblo, CO, USA. Chemical Geology, 191(4), 305-327.

Dardenne, M. A. (1978). Síntese sobre a estratigrafia do Grupo Bambuí no Brasil Central. XXX Congresso Brasileiro de Geologia, v. 2, 597-610. Recife: SBG. 
Dardenne, M. A. (1981). Os grupos Paranoá e Bambuí na Faixa Dobrada Brasília. I Simpósio sobre o Cráton do São Francisco, 140-157. Salvador: SBG/Núcleo BA.

Delgado, I. M., Souza, J. D., Silva, L. C., Silveira Filho, N. C., Santos, R. A., Pedreira, A. J., Guimarães, J. T., Angelim, L. A. A., Vasconcelos, A. M., Gomes, I. P., Lacerda Filho, J. V., Valente, C. R., Perrotta, M. M., Heineck, C. A. (2002). Escudo Atlântico. In: L. A. Bizzi, C. Schobbenhaus, M. Vidotti, J. H. Gonçalves (Eds.), Geologia, Tectônica e Recursos Minerais do Brasil. Brasília: CPRM. DVD.

DePaolo, D. J. (1981). Neodymium isotopes in the Colorado Front Range and crust mantle evolution in the Proterozoic. Nature, 291, 193-196.

Dias, P. H. A., Noce, C. M., Pedrosa-Soares, A. C., Seer, H. J., Dussin, I. A., Valeriano, C. M., Kuchenbecker, M. (2011). O Grupo Ibiá (Faixa Brasília Meridional): evidências isotópicas $\mathrm{Sm}-\mathrm{Nd}$ e $\mathrm{U}-\mathrm{Pb}$ de bacia colisional tipo flysch. Geonomos, 19(2), 90-99.

Einsele, G. (1992). Sedimentary basins: evolution, facies and sediment budget. New York: Springer-Verlag.

Elholou, S., Belousova, E., Griffin, W. L., Peasom, N. J., O'Reilly, S. Y. (2006). Trace element and isotopic composition of GJ red zircon standard by laser ablation. Geochimica and Cosmochimica Acta, 70(18), 158.

Fernandes, R. A., Carneiro, M. A. (2000). O Complexo Metamórfico Campo Belo (Cráton São Francisco Meridional): unidades litodêmicas e evolução tectônica. Revista Brasileira Geociências, 30(4), 671-678.

Fugita, A. M., Clark Filho, J. G. (2001). Recursos Energéticos da Bacia do São Francisco: Hidrocarbonetos líquidos e gasosos. In: C. P. Pinto, M. A. Martins-Neto (Eds.), Bacia do São Francisco: Geologia e Recursos Naturais (265-284). Belo Horizonte, SBG/MG.

Klein, P. B. W. (2008). Geoquimica de rocha-total, geocronologia de U-Pb, e geologia isotópica de $\mathrm{Sm}-\mathrm{Nd}$ das rochas ortognáissicas e unidades litológicas associadas da região de Ipameri-Catalão (Goiás). Tese (Doutorado). Brasília: Instituto de Geociências - UnB.

Kuchenbecker, M. (2011). Quimioestratigrafia e Proveniência Sedimentar da porção basal do Grupo Bambuí em Arcos (MG). Dissertação (Mestrado). Belo Horizonte: Instituto de Geociências - UFMG.
Kuchenbecker, M., Babinski, M., Pedrosa-Soares, A. C., Lopes-Silva, L. L., Pimenta, F. High-resolution chemostratigraphy of the lower Bambuí Group, São Francisco craton, Brazil: Insights on Gondwanaland palaeoenvironments. (no prelo).

Kuchenbecker, M., Lopes-Silva, L. L., Pimenta, F., Pedrosa-Soares, A. C., Babinski, M. (2011). Estratigrafia da porção basal do Grupo Bambuí na região de $\operatorname{Arcos}(\mathrm{MG})$ : uma contribuição com base em testemunhos de sondagem. Geologia USP - Série Cientifica, 11(2), 45-54.

Martins, M., Teixeira, L. B., Braun, O. P. G. (1993). Bacia do São Francisco: uma fronteira exploratória na pesquisa de petróleo do Brasil. VII Simpósio de Geologia de Minas Gerais, 55-57. Ouro Preto: SBG.

Martins-Neto, M. A. (2009). Sequence stratigraphic framework of Proterozoic successions in eastern Brazil. Marine and Petroleum Geology, 26(2),163-176.

Martins-Neto, M. A., Alkmim, F. F. (2001). Estratigrafia e evolução tectônica das bacias neoproterozóicas do Paleocontinente São Francisco e suas margens: Registro da quebra de Rodínia e colagem de Gondwana. In: C. P. Pinto, M. A. Martins-Neto (Eds.), Bacia do São Francisco: Geologia e Recursos Naturais (31-54). Belo Horizonte: SBG/MG.

Martins-Neto, M. A., Lima, S. A., Pedrosa-Soares, A. C. (2001). Tectono-sedimentary evolution of sedimentary basins from Late Paleoproterozoic to Late Neoproterozoic in the São Francisco craton and Araçuaí fold belt, eastern Brazil. Sedimentary Geology, 141-142.

McLennan, S. M.(1989). Rare earthelements in sedimentary rocks: Influence of provenance and sedimentary processes. Reviews in Mineralogy and Geochemistry, 21, 169-200.

Nobre-Lopes, J. (1995). Faciologia e gênese aos carbonatos do Grupo Bambuí na região de Arcos, Estado de Minas Gerais. Dissertação (Mestrado). São Paulo: Instituto de Geociências - USP.

Paula-Santos, G. M., Babinski, M., CaetanoFilho, S., Kuchenbecker, M. (2012). Abordagem quimioestratigráfica $(\mathrm{C}, \mathrm{O})$ e geocronológica da Formação Sete Lagoas na região de Vespasiano, MG: uma unidade cambriana?. XLVI Congresso Brasileiro de Geologia. Santos: SBG. 
Pimentel, M. M., Della Giustina, M. E. S., Rodrigues, J. B., Junges, S. L. (2012). Idades dos grupos Araxá e Bambuí: Implicações para a evolução da Faixa Brasília. XLVI Congresso Brasileiro de Geologia. Santos: SBG.

Pimentel, M. M., Fuck, R. A., Jost, H., Ferreira Filho, C. F., Araújo S. M. (2000).The basement of the Brasília Belt and the Goiás Magmatic Arc. In: U. G. Cordani, E. J. Milani, A. Thomaz Filho, D. A. Campos (Eds.), Tectonic Evolution of South America (195-230). Rio de Janeiro: 31 International Geological Congress.

Reis, H. L. S. (2011). Estratigrafia e Tectônica da Bacia do São Francisco na zona de emanações de gás natural do baixo Rio Indaiá (MG). Dissertação (Mestrado). Ouro Preto: Departamento de Geologia - UFOP.

Reis, H. L. S., Alkmim, F. F., Silva, L. C. (2012). O Cinturão neoproterozoico de antepaís da Faixa Brasília, Bacia do São Francisco (Brasil) - Características e principais traços tectonicos. XLVI Congresso Brasileiro de Geologia. Santos: SBG.
Rodrigues, J. B. (2008). Proveniência de sedimentos dos grupos Canastra, Ibiá, Vazante e Bambui - Um estudo de zircões detríticos e idades modelo $\mathrm{Sm}-\mathrm{Nd}$. Tese (Doutorado). Brasília: Instituto de Geociências - UnB.

Seer, H., Moraes, L. C., Junges, S. L. (2010). Novos dados $\mathrm{U}-\mathrm{Pb}$ e Sm-Nd de granitos intrusivos no Grupo Araxá, Faixa Brasília Meridional, entre a região de Araxá e Monte Carmelo, MG. XLV Congresso Brasileiro de Geologia. Belém: SBG.

Silva, L. C. (2006). Geocronologia aplicada ao mapeamento regional, com ênfase na técnica $U-P b$ SHRIMP e ilustrada com estudos de casos brasileiros. Brasília: CPRM.

Tucker, M. E. (2003). Sedimentary rocks in the field. Chichester: John Wiley \& Sons Ltd.

Wilcox, D., Dove, B., McDavid, D., Greer, D. (2002). Image Tool for Windows. University of Texas Health Science Centre, San Antonio. Acesso em 29 de janeiro de 2013, <http://ddsdx.uthscsa.edu/dig/itdesc.html>. 